\title{
Management of Candidiasis in an Indian Parakeet
}

\author{
S. Divya* and M. Areshkumar \\ AK Pet Clinic, Chennai, Tamil Nadu, India \\ *Corresponding author:
}

\begin{abstract}
A B S T R A C T
Keywords

Candidiasis, Ketoconazole, Indian parakeet.

Article Info

Accepted:

17 April 2017 Available Online: 10 May 2017

A ten months old female parakeet reported with the history of in appetence, leukoid plaques around commissures of the mouth and oral cavity. Clinical examination revealed that leukoid plaques were noticed on the tongue and commissures of mouth. All other vital parameters were normal. The parakeet was treated with tablet ketoconazole @ $50 \mathrm{mg} / \mathrm{kg}$ body weight orally for 7 days along with vitamin and mineral supplements. After a week of treatment plaques were subsided and parakeet recovered uneventfully.
\end{abstract}

\section{Introduction}

Candida albicans is the yeast normally found in the healthy birds as commensal organism which is present in the digestive, urinary and reproductive tracts (Mancianti et al., 2002). It is a very common cause of stomatitis in birds, particularly in young, immunosuppressed birds, those on antibiotics and in lorikeets because of the high sugar content of some nectar mixes.

The primary fungi of concern to the avian practitioner are Candida albicans and Aspergillus fumagatis. Candida albicans is more commonly seen in birds kept in high humidity and warm temperatures. It is more prevalent in birds being hand-reared and kept in brooders, and in birds kept in tropical climates (Tully et al., 2000). Candida is an opportunistic parasite, hence takes upper hand when the bird become ill or stressed and also prolonged use of antibiotics, vitamin A deficiency, trichomoniasis, unhygienic conditions and avian pox (Speer, 1995; Schmidt et al., 2003; Godoy, 2007).

Candida causes lesions around the commissures of the mouth and nares and occasionally around feather follicles on the head, back and ventral abdomen. Price et al., (1982) reported that the candida spp. producing hydrolytic enzymes, which makes the species easier its penetration into tissues and favors their pathogenicity. The appearance of the lesions known as 'cotton mouth' as the candida plaques can look like threads of cotton wool spread on the mucous membranes.

A 10 months old female Indian parakeet reported with the history of in appetence, 
leukoid plaques around commissures of the mouth and oral cavity.

\section{Clinical observation and diagnosis}

On collection of history, it was noticed that the bird was hand fed with bread and some house hold food and fruits (Fig. 1a). Clinical examination revealed that leukoid plaque was noticed on the tongue and commissures of mouth (Fig. 1b). All other vital parameters were normal.

Samples were collected on glass slide and examined under microscope after staining with methylene blue (Fig. 1c).

\section{Treatment and out come}

The parakeet was treated with tablet ketoconazole @ $50 \mathrm{mg} / \mathrm{kg}$ body weight (Tully et al., 2000) orally once a day along with vitamin and mineral supplements. Advised the owner not to hand feed the parakeet with bread and to provide healthy and nutritious food. After 7 days of treatment the plaques was subsided and animal is doing well.

\section{Results and Discussion}

Candidiasis is evidenced by large numbers of typical organisms. Candida can be a normal inhabitant of the upper alimentary tract, hence low numbers of organisms do not produce inflammation. An inflammatory response often occurs when the infection has involved themucosa. The presence of hyphae formation suggests a potential systemic invasion by the yeast (Doneley, 2010).

Fig.1(a) Bird suffered with candidial plaque (b) Leukoid plaque on the tongue and commissures of mouth (c) Microscopic examination methylene blue stain

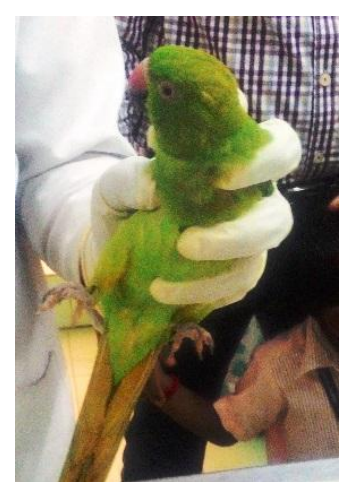

(a)

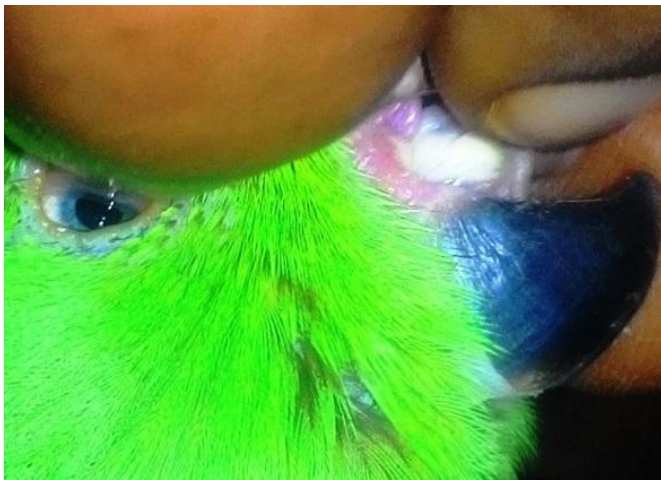

(b)

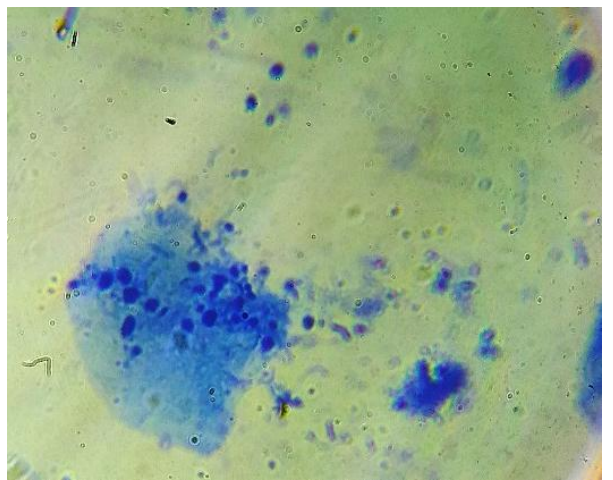

(c)
Candida albicans is often detected by Gram stain in the droppings of birds eating yeastcontaining feedstuffs (e.g. bread, biscuits). Unless the yeast are numerous and budding, or can be cultured in heavy numbers, they have little or no clinical significance. Development of pseudohyphae, seen on Gram staining, is significant and may indicate invasion of the intestinal mucosa by the yeast
(Doneley, 2010). In this case the methylene blue staining technique was useful in detecting the organism quickly (Kucsera et al., 2000).

Although, most veterinary texts consider $C$. albicans as the only species of the genus involved in the infections of the digestive tract of psittacines birds (Harrison, 1986; 
Speer, 1995; Schmidt et al., 2003). Vieira and Selene (2009) reports species non-albicans of the genus Candida as responsible for infections in birds. The bird responded well to the ketoconazole at the dose rate of $50 \mathrm{mg} / \mathrm{kg}$ body weight and complete recovery was noticed in seven days.

Nutritional problems, especially those resulting from an unbalanced diet, are often seen in mixed aviaries and individual pet finches. All carnivorous birds need a certain amount of supplementation by an egg-food or 'soft bill' food, as an unbalanced diet predisposes birds to health problems, especially with Enterobacteriaceae (e.g. $E$. coli, Klebsiella spp. and Enterobacter spp.) and yeast infections (especially Candida albicans). The breeding results are poor in birds with an unbalanced diet (Tully et al., 2000a).

The risk of candidiasis can be prevented by providing a clean environment and proper nutrition, reducing or eliminating any causes of stress, and preventing contact with any potentially sick bird.

\section{References}

Doneley, B. 2010. In: Interpreting Diagnostic Tests, Avian Medicine and Surgery in Practice (Companion and aviary birds. Manson Publishing Ltd), Pp: 83.

Godoy, S.N. 2007. Psittaciformes. In: Cubas Z.S., Silva J.C.R. \& Catão-Dias J.L. Eds), Tratado de Animais Selvagens:
Medicinaveterinária. Roca, São Paulo. P: 222-251.

Harrison G.J. 1986. Clinical Avian Medicine and Surgery, W.B. Saunders, Philadelphia. PP: 717.

Kucsera, J., K. Yarita and K. Takeo. 2000. Simple detection method for distinguishing dead and living yeast colonies. J. Microbiol. Methods, 41(1): pp: 19-21.

Mancianti, F., S. Nardoni and R. Ceccherelli. 2002. Occurrence of yeasts in psittacines droppings from captive birds in Italy. Mycopathologia, 153. pp: 121-124.

Price, M.F., I.D. Wilkinson and L.O. Gentry. 1982. Plate method for detection of phospholipase activity in Candida albicans. Sabouraudia, 20: pp. 7-14.

Schmidt, R.E., D.R. Reavill and D.N. Phalen. 2003. Pathology of Pet and Aviary Birds. Iowa State Univ. Press, Ames, Pp: 234.

Speer, B.L. 1995. Infectious diseases. In: Abramson J., Speer B.L. \& Thomsen J.B. Eds), The Large Macaws: Their care, breeding and conservation. Raintree Publications, Fort Bragg. p. 310

Tully, Jr. T.N., G.M. Dorrestein and A.K. Jones. 2000. In: Fungal diseases, Hand book of Avian Medicine, $2^{\text {nd }}$ Edi. Reed Educational and Professional Publishing Ltd. Pp: 138.

Tully, Jr.T.N., G.M. Dorrestein and A.K. Jones. 2000a. In: Metabolic and nutritional disorders, Hand book of Avian Medicine, $2^{\text {nd }}$ Edi. Reed Educational and Professional Publishing Ltd. Pp: 161.

Vieira, R.G. and D.A.C. Selene. 2009. Phenotypical characterization of Candida spp. Isolated from crop of parrots (Amazona spp). Pesq. Vet. Bras., 29(6) pp. 452-456.

\section{How to cite this article:}

Divya, S., and Areshkumar, M. 2017. Management of Candidiasis in an Indian Parakeet. Int.J.Curr.Microbiol.App.Sci. 6(5): 1395-1397. doi: https://doi.org/10.20546/ijcmas.2017.605.151 